NASA Technical Memorandum 113123

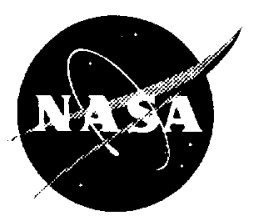

\title{
Photodetector Development for the Wheel Abrasion Experiment on the Sojourner Microrover of the Mars \\ Pathfinder Mission
}

David M. Wilt

Lewis Research Center, Cleveland, Ohio

Phillip P. Jenkins

Essential Research, Inc., Cleveland, Ohio

David A. Scheiman

NYMA, Inc., Brook Park, Ohio

Prepared for the

32nd Intersociety Energy Conversion Engineering Conference cosponsored by AIChE, ANS, SAE, AIAA, ASME, and IEEE

Honolulu, Hawaii, July 27-August 1, 1997

National Aeronautics and

Space Administration

Lewis Research Center 
Trade names or manufacturers' names are used in this report for identification only. This usage does not constitute an official endorsement, either expressed or implied, by the National Aeronautics and Space Administration.

Available from

NASA Center for Aerospace Information 800 Elkridge Landing Road

Linthicum Heights, MD 21090-2934

Price Code: A03
National Technical Information Service 5287 Port Royal Road Springfield, VA 22100 Price Code: A03 


\title{
PHOTODETECTOR DEVELOPMENT FOR THE WHEEL ABRASION EXPERIMENT ON THE SOJOURNER MICROROVER OF THE MARS PATHFINDER MISSION
}

\author{
David M. Wilt, Phillip P. Jenkins', David A. Scheiman² \\ NASA Lewis Research Center \\ 21000 Brookpark Rd, M.S. 302-1 \\ Cleveland, Ohio \\ Phone (216) 433-6293, Fax (216) 433-6106 \\ 'Essential Research, Inc. \\ 23811 Chagrin Blvd. \#220 \\ Cleveland, Ohio \\ (216) 831-0177 \\ ${ }^{2}$ NYMA, Inc. \\ 2001 Aerospace Parkway \\ Brook Park, Ohio 44142
}

\begin{abstract}
On-board the Mars Pathfinder spacecraft, launched in December of 1996, is a small roving vehicle named Sojourner. On Sojourner is an experiment to determine the abrasive characteristics of the Martian surface, called the Wheel Abrasion Experiment (WAE). The experiment works as follows: one of the wheels of the rover has a strip of black anodized aluminum bonded to the tread. The aluminum strip has thin coatings of aluminum, nickel and platinum deposited in patches. There are five (5) patches or samples of each metal, and the patches range in thickness from $200 \AA$ to $1000 \AA$. The different metals were chosen for their differing hardness and their environmental stability. As the wheel is spun in the Martian soil, the thin patches of metal are abraded away, exposing the black anodization. The abrasion is monitored by measuring the amount of light reflected off of the samples. A photodefector was developed for this purpose, and that is the subject of this paper.
\end{abstract}

\section{INTRODUCTION}

The photodetector is attached to the arm or "bogie" which supports the rover center-right wheel (fig. 1). The constrains placed upon the design of the photodetector were as follows: mass budget of $10 \mathrm{~g}$, physical size of $1 \mathrm{~cm}$ $\times 1 \mathrm{~cm} \times 1 \mathrm{~cm}$, must operate in the photovoltaic mode (unpowered), imaging limited to one sample $(1.5 \mathrm{~cm} x$ $2.5 \mathrm{~cm}$ ), able to withstand $60 \mathrm{~g}$ landing load, able to withstand launch vibrational environment, able to operate at $-50^{\circ} \mathrm{C}$, and obviously able to detect small changes in the reflectivity of the abrasion samples.

Several photodetector designs were considered. The initial development focused on a detector which utilized a black anodized honeycomb aluminum extrusion for restricting the field of view of the detector. Several extrusions were found with suitable cell sizes $(-1.5 \mathrm{~mm})$, unfortunately the black anodization did not produce a surface which was optically black at high angles of incidence. We observed that multiple reflections within the honeycomb increased the acceptance angle of the detector, making this design unsuitable for the mission.

\section{DETECTOR DESIGN}

The final photodetector design (fig. 2) utilized geometrical optics and included three (3) small $(2 \mathrm{~mm} \times$ $4 \mathrm{~mm}$ ) gallium arsenide (GaAs) solar cells wired in parallel and connected to a load resistor. Geometrical optics limited the field of view to slightly smaller than one abrasion sample $(1.5 \mathrm{~cm} \times 2.5 \mathrm{~cm})$ as viewed at an angle of incidence of $30^{\circ}$ and a separation distance of $19.2 \mathrm{~mm}$ (center of sample to front of detector). The photodetector ray tracing design is shown in fig. 3 . This approach was utilized to determine the size and location of the GaAs cells and the openings in the aperture plate.

Alignment of the photodetector optics was accomplished by machining a step in the bottom of the photodetector housing. This step was used to locate the circuit board which held the GaAs solar cells. Black anodized aluminum baffle plates were incorporated to optically isolate each of the three detectors. The aperture plate (not shown) was also located by means of a step machined in the top of the photodetector housing. All of the components of the photodetector housing were fabricated from 7075-T6 aluminum which was black anodized (MIL-A-8625-F, type II, class 2). 


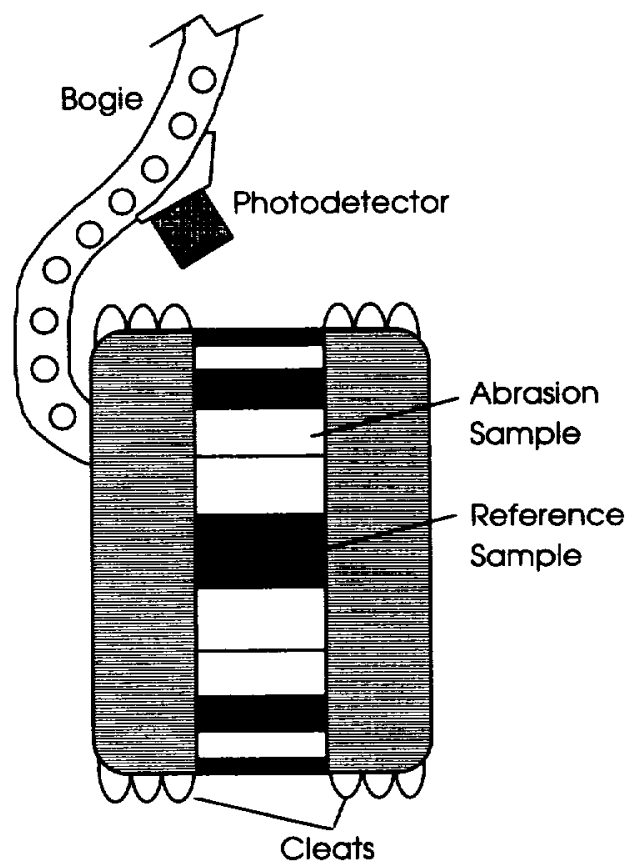

FIGURE 1 - OVERVIEW OF WAE EXPERIMENTAL SET-UP.

The following materials were used in the construction of the detector:

- Gallium arsenide (GaAs) on germanium (Ge) solar cells $(4.25 \mathrm{~mm} \times 2.0 \mathrm{~mm})$

- Kovar solar cell interconnects

- $0.021^{n}, 1$ oz. MIL-S-13949H-A1/4D circuit board, tinned

- DC 93-500 silicon adhesive (cover glass)

- DC RTV 566 silicon potting compound

- 1.26 kohm surface mount resistor, MIL-R$55342,0.1 \%$ tolerance, $0.01 \% / 1000$ hours Life Failure Rate.

- 28 AWG Teflon insulated wire, Type ET-MIL-W1687E/6

- 7075-T6 aluminum, black anodized to MIL-A8625-F, type II, class 2

- Hysol EA 9394 epoxy

- G10 fiberglass mount with (2) gold plated bifurcated terminals (supplied by JPL)

\section{PHOTODETECTOR TESTING}

The photodetector design was tested using a prototype detector, fabricated with available LPE GaAs solar cells, and secured to a fixture which maintained the correct sample-detector spatial and angular separation. The fixture also permitted the abrasion sample to be curved to the appropriate radius.

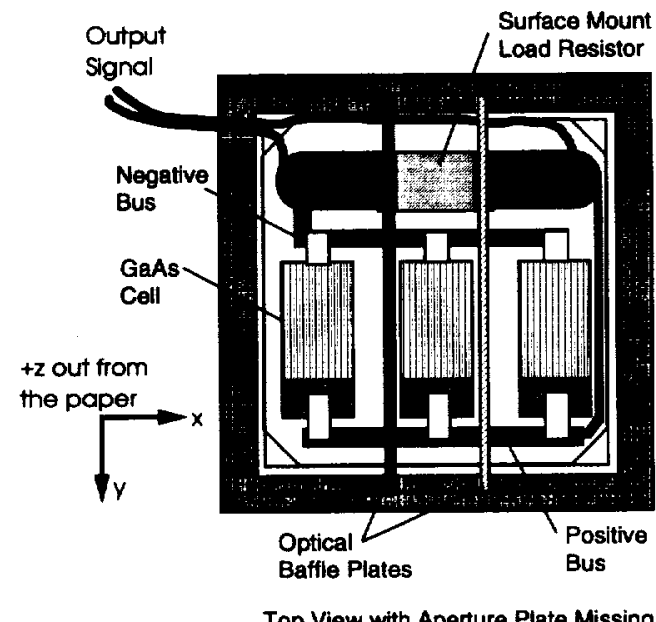

FIGURE 2 - TOP VIEW OF PHOTODETECTOR WITH APERTURE PLATE MISSING.

This fixture was mounted on a sun tracker which contained direct and global solar insolation measurement equipment. The prototype fixture also contained a rotation stage which permitted the incidence angle of the sun to be varied about three (3) axis'.

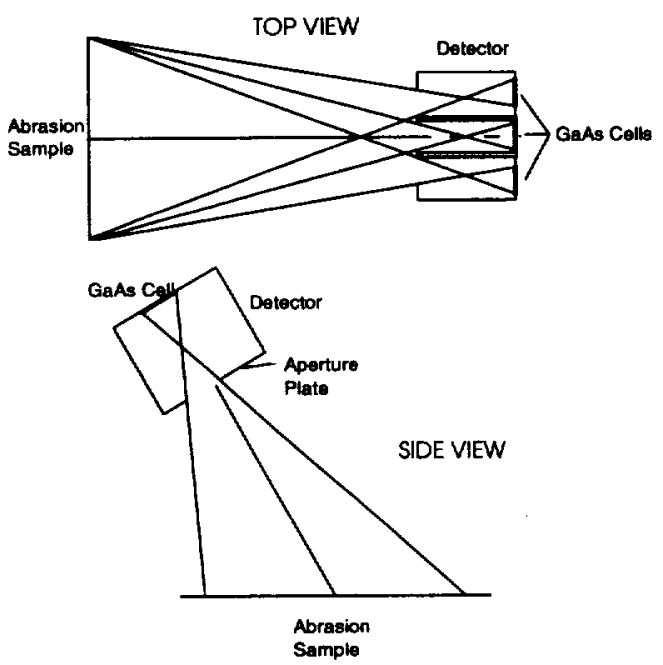

FIGURE 3 - RAY TRACING DESIGN OF PHOTODETECTOR

Several different abrasion samples were used to determine both the max. response and the angular dependence of the WAE experimental set-up. The first measurements were performed using aluminum foil, since Al has the highest reflectivity of the three (3) selected abrasion materials, in the wavelength range of interest. 
Once the actual flight samples became available they were also used to further define the characteristics of the WAE experiment. A set of measurements were also made with palaginite dust coated samples. This data is shown in figure 4 . The rotational axis are: alpha - rotation about the rover centerline (angle of incidence); beta rotation about the wheel axle; gamma - rotation about the normal to the sample directly under the detector. The $y$ axis units represent the response to the direct component of illumination (i.e. measurements made on a clear day, $>90 \%$ direct insolation, $<10 \%$ diffuse).

Based on this data, we estimate:

Max. Response $=5 \mu \mathrm{Acm} / \mathrm{mW}\left(@ 0^{\circ} \mathrm{C}\right)$

Max. Illumination $=40 \mathrm{~mW} / \mathrm{cm}^{2}$ - Based on projected operation at $1400 \mathrm{hr}$. on a clear day (Tau $=0.5)$ (JPL data)

Temp. Coe. $(\mathrm{lsc})=0.067 \% /^{\circ} \mathrm{C}$ - Based on actual SR vs. Temp. measurements of ASEC GaAs/Ge cells.

Operating Temp. $=-30^{\circ} \mathrm{C}$ (JPL Data)

Sample $=$ Al film with light dusting

Iscmax $=196 \mu \mathrm{A}$

To be conservative, in sizing the load resistor we chose to limit the max. voltage to $250 \mathrm{mV}$ thus,

$$
\begin{aligned}
R & =0.25 \mathrm{~V} / 1.96 \mathrm{e}-4 \mathrm{~A} \\
& =1.275 \mathrm{kohm}
\end{aligned}
$$

The data in figure 4 shows several interesting features. First of all, the aluminum foil demonstrates a higher specular reflectance characteristic than the $900 \AA$ Al film. Secondly, the addition of the palaginite (Mars simulant) dust to the Al film reduces the specular component of the reflection but has little effect on the diffuse component as noted by the reduction in peak height and increase in peak width. Based on this detector characterization, a pointing tolerance of $+/-15^{\circ}$ has been established for the mission.

\section{PHOTODETECTOR TEST PLAN}

The following test plan was developed to quality the photodetector design (qualification testing) and to verify the flight worthiness of the actual flight hardware (flight acceptance testing).

\section{Vibration Testing}

Qualification Testing

1) Epoxy test photodetector unit to aluminum test fixture adapter plate.

2) Test assembly at Qualification Levels for 3

minutes/axis. (JPL supplied profile)

3) Check response of detector to standard input ( $\mathrm{He}-\mathrm{Ne}$ laser).
Flight Acceptance Testing

1) Secure detector Flight Unit (FU) to test fixture with temporary hold-down (clamp)

2) Test assembly at Acceptance Levels for 1 minute/axis. (JPL supplied profile)

3) Check response of Detector to standard input ( $\mathrm{He}-\mathrm{Ne}$ laser).
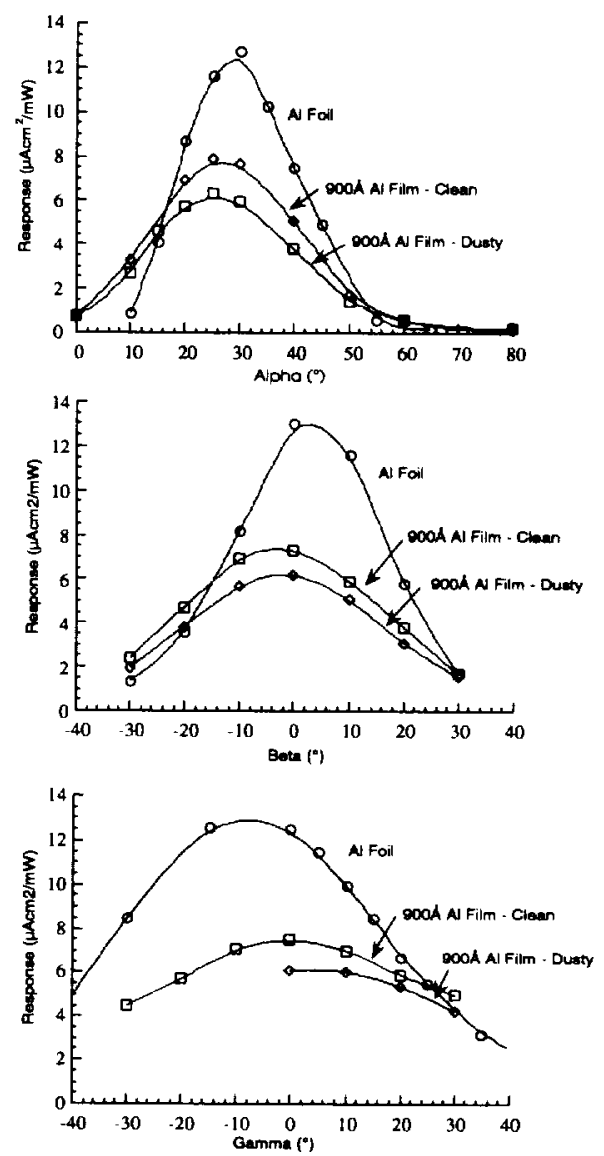

FIGURE 4 - PHOTODETECTOR CHARACTERIZATION PROFILES FOR ROTATION ABOUT ALPHA (ROTATION ABOUT THE ROVER CENTERLINE, I.E. ANGLE OF INCIDENCE), BETA (ROTATION ABOUT THE WHEEL AXLE) AND GAMMA (ROTATION ABOUT THE NORMAL TO THE SAMPLE DIRECTLY UNDER THE DETECTOR) FOR DIFFERENT ABRASION SAMPLES.

\section{Low Frequency Load Testing}

Qualification Testing

1) Epoxy test Photodetector unit to aluminum test fixture adapter plate.

2) Test assembly at Qualification Levels (60g) in the $+z$ direction and $+/-x$ direction. 
3) Check response of Detector to standard input ( $\mathrm{He}-\mathrm{Ne}$ laser).

Flight Acceptance Testing

1) Secure Detector Flight Unit (FU) to test fixture with temporary hold-down (clamp, etc.)

2) Test assembly at Acceptance Levels (60g) in the $+z$ direction. (see fig. 2)

3) Check response of Detector to standard input ( $\mathrm{He}-\mathrm{Ne}$ laser).

\section{Thermal Testing}

Qualification Testing

1) Epoxy test Photodetector unit to aluminum test fixture adapter plate.

2) Test assembly at Oven Levels:

Ambient: 760 torr dry nitrogen

Low temp.: $-110^{\circ} \mathrm{C}, 1$ hour dwell

High temp.: $+40^{\circ} \mathrm{C}, 1$ hour dwell

Transition Time: 1 hour

Cycles: $\mathbf{3}$

Detector shall be illuminated during

transition from low to high temp. to

check continuity.

3) Check response of Detector to standard input (He-Ne laser).

4) Test assembly at Life Cycle Levels:

Ambient: 760 torr dry nitrogen

Low temp.: $-100^{\circ} \mathrm{C}$, no dwell

High temp.: $+30^{\circ} \mathrm{C}$, no dwell

Transition Time: 1 hour

Cycles: 35

5) Check response of Detector to standard input ( $\mathrm{He}-\mathrm{Ne}$ laser).

Flight Acceptance Testing

1) Secure Detector Flight Unit (FU) to test fixture with temporary hold-down (clamp, etc.)

2) Test assembly at Acceptance Levels: Ambient: 760 torr dry nitrogen Low temp.: $-95^{\circ} \mathrm{C}, 1$ hour dwell Mid temp.: $-60^{\circ} \mathrm{C}, 1$ hour dwell

High temp.: $+25^{\circ} \mathrm{C}, 1$ hour dwell

Transition Time: 1 hour between settings

Cycles: 1

Detector illuminated at Mid temp. setting to check continuity.

3) Check response of Detector to standard input ( $\mathrm{He}-\mathrm{Ne}$ laser).

\section{Vacuum Testing}

Qualification Testing

1) Epoxy test Photodetector unit to aluminum test fixture adapter plate.
2) Subject test assembly to a pressure of less than 1 torr for a minimum of 24 hours at a temperature of $40^{\circ} \mathrm{C}$.

3) Check response of Detector to standard input (He-Ne laser).

Flight Acceptance Testing

1) Secure Detector Flight Unit (FU) to test fixture with temporary hold-down (clamp, etc.)

2) Subject test assembly to a pressure of less than 1 torr for a minimum of 24 hours at $40^{\circ} \mathrm{C}$.

3) Check response of Detector to standard input

\section{Planetary Protection}

FU shall be baked at $110^{\circ} \mathrm{C}$ for a min. of 50 hours.

\section{FLIGHT UNIT CALIBRATION}

The flight unit (FU) utilized GaAs/Ge solar cells bonded to the circuit card by Applied Solar Energy Corporation (now TECSTAR). These devices demonstrated a significantly higher responsivity that the LPE GaAs cells used to size the load resistor. As such, the maximum output voltage of the detector has been increased to $400 \mathrm{mV}$. Testing has indicated that the detector begins to saturate at $500 \mathrm{mV}$ (under room temperature testing), thus we feel confident that that under actual operating conditions (i.e. low temperature, dust obscuration, rover misalignment) the detector will always be operating in its linear region.

Figure 5 shows the actual calibration curve for the FU detector with the FU wheel. This test was conducted using a photographic test lamp (750W tota light) which produced approximately 0.25 Mars solar insolation. The sample pattern for each metal is: reference / $200 \mathrm{~A}$ film / reference / $300 \AA$ film / $450 \AA$ film / reference / $700 \AA$ film / $1000 A$ film, as viewed in order of increasing wheel rotational angle. This pattern was chosen so that each abrasion sample would be adjacent to a blank reference area, with the thinnest sample bounded on both sides by a reference sample.

There are several features of note in the calibration data. Firstly, none of the thin metal samples are opaque. This is shown in the increasing reflectance as the sample thickens. Secondly, the peaks demonstrate a tine structure which is caused by variations in the abrasion sample surface. These variations are attributed to the process by which the samples were pre-bent and glued to the wheel.

Finally, the blank samples do not produce a zero output from the photodetector. Figure 6 shows both the spectral reflectance from the black anodized aluminum and the spectral response from a GaAs cell. The black anodization has a fairly low reflectance $(<5 \%$ ) up to $700 \mathrm{~nm}$, at which point it begins to reflect. By the 
bandedge of GaAs (870nm), the reflectance has increased to $>40 \%$. This reflectance accounts for the non-zero reference value.

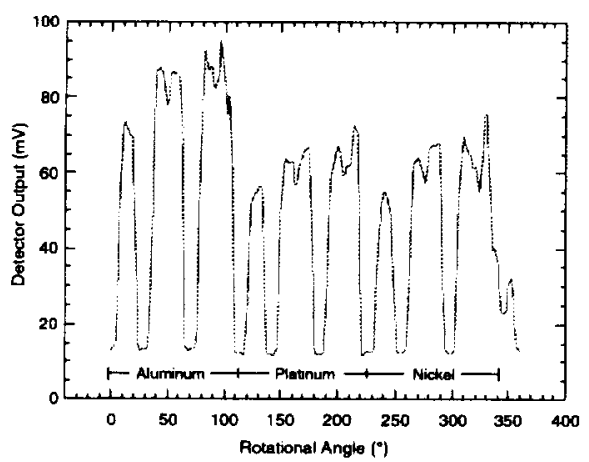

FIGURE 5 - CALIBRATION DATA FOR THE FLIGHT UNIT WHEEL AND DETECTOR UNDER 0.25 MARS ILLUMINATION. THERE ARE FIVE (5) ABRASION SAMPLES FOR EACH METAL.

\section{ACKNOWLEDGMENT}

The authors would like to thank Frank DeAngelo and Dr. Dennis Flood of NASA LeRC for their enthusiastic support of this development and our involvement with the Mars/Pathfinder project.

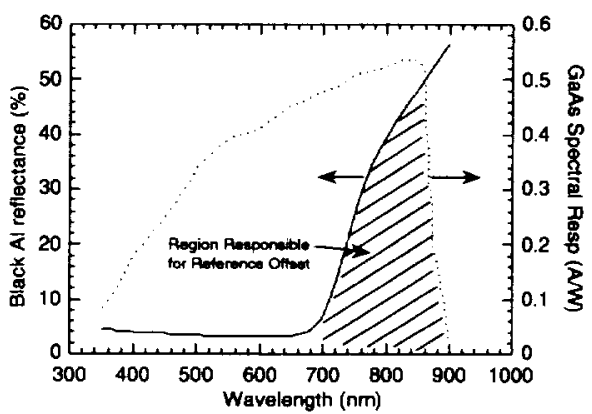

FIGURE 6 - GAAS SPECTRAL RESPONSE AND ANODIZED ALUMINUM SPECTRAL REFLECTANCE. THE CROSS HATCHED REGION SHOWS THE REASON FOR THE NON-ZERO REFERENCE VALUE.

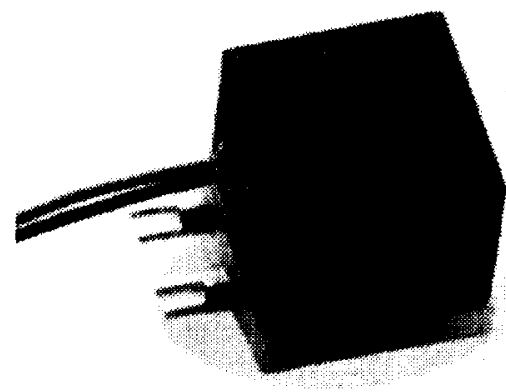

FIGURE 7 - PHOTOGRAPH OF THE FU DETECTOR. THE BIFURCATED TERMINALS SHOWN IN THE BACKGROUND WERE USED FOR INTERFACING THE DETECTOR TO THE ROVER ELECTRONICS. 


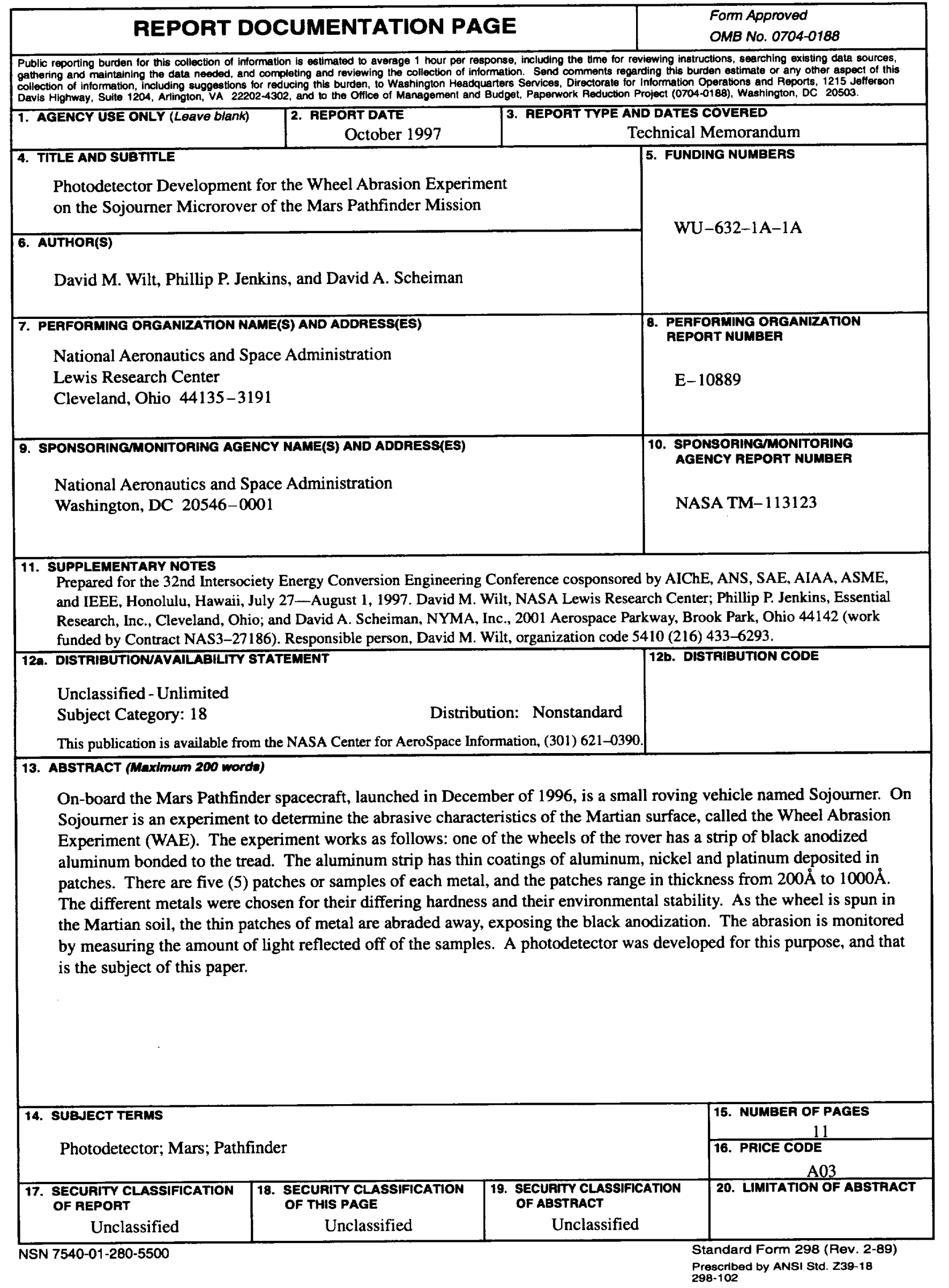

